\title{
1 Viability of MS2 and Phi6 Bacteriophages on Carpet and Dust
}

2

3 Nicholas Nastasi ${ }^{1,2,3}$, Nicole Renninger ${ }^{2}$, Ashleigh Bope ${ }^{1,2,3}$, Samuel J. Cochran ${ }^{1,2,3}$, Justin

4 Greaves $^{4}$, Sarah R. Haines ${ }^{1,2,3}$, Neeraja Balasubrahmaniam ${ }^{1,2,3}$, Katelyn Stuart ${ }^{3}$, Jenny Panescu ${ }^{2}$,

5 Kyle Bibby $^{4}$, Natalie M. Hull ${ }^{2,5}$, Karen C. Dannemiller ${ }^{2,3,5 *}$

1. Environmental Sciences Graduate Program, Ohio State University, Columbus, OH 43210

2. Department of Civil, Environmental \& Geodetic Engineering, College of Engineering, Ohio State University, Columbus, OH 43210

3. Division of Environmental Health Sciences, College of Public Health, Ohio State University, Columbus, OH 43210

4. Department of Civil \& Environmental Engineering \& Earth Sciences, College of Engineering, University of Notre Dame, Notre Dame, IN 46556

5. Sustainability Institute, Ohio State University, Columbus, OH 43210

*Corresponding author: Karen C. Dannemiller, Department of Civil, Environmental \& Geodetic Engineering, Environmental Health Sciences, Sustainability Institute, Ohio State University, 470 Hitchcock Hall, 2070 Neil Ave, Columbus, OH 43210, Dannemiller.70@osu.edu, 614-292-4031

(1)

(1)

(1)

(3)

.




\section{Abstract}

Respiratory viral illnesses are commonly spread in the indoor environment through

43 multiple transmission routes, including droplets, aerosols, and direct/indirect contact. Indoors,

44 resuspension of dust from flooring is a major source of human exposure. However, it is critical to

45 determine viral persistence on dust and flooring to better characterize human exposure. The goal

46 of this work is to determine viral viability on two carpet types (cut and looped) and house dust

47 over time and after four different cleaning methods. MS2 and Phi6 bacteriophages were used to

48 represent non-enveloped and enveloped viruses, respectively. These viral surrogates were placed

49 in an artificial saliva solution and nebulized onto carpet or dust. Viability was measured at

50 various time points $(0,1,2,3,4,24$, and 48 hours) and after cleaning (vacuuming, hot water

51 extraction with stain remover, steam, and a disinfection spray). Viability decay was modeled as

52 first-order. MS2 bacteriophages showed slower viability decay rates in dust $\left(-0.11 \mathrm{hr}^{-1}\right)$, cut

53 carpet $\left(-0.20 \mathrm{hr}^{-1}\right)$, and looped carpet $\left(-0.09 \mathrm{hr}^{-1}\right)$ compared to Phi6 $\left(-3.36 \mathrm{hr}^{-1},-1.57 \mathrm{hr}^{-1}\right.$, and -

$540.20 \mathrm{hr}^{-1}$ respectively). The difference between phages was statistically significant in dust and cut

55 carpet $(\mathrm{p}<0.05)$. Viral RNA demonstrated minimal degradation that in most cases was not

56 statistically different from zero over the 48 hours measured ( $>>0.05)$. Viable viral concentrations

57 were reduced to below the detection limit for steam and disinfection for both MS2 and Phi6

$58(\mathrm{p}<0.05)$, while vacuuming and hot water extraction with stain remover showed no significant

59 changes in concentration from uncleaned carpet $(\mathrm{p}>0.05)$. This study used viral surrogates and

60 did not model risk of viral transmission via dust. Overall, these results demonstrate that MS2 and

61 Phi6 bacteriophages can remain viable in carpet and dust for several hours to days, and cleaning

62 techniques with heat and disinfectants may be more effective than standard vacuuming for viral 
63 removal. Future work should model risk from exposure via dust and flooring for various viruses

64 such as influenza, SARS-CoV-2, and RSV.

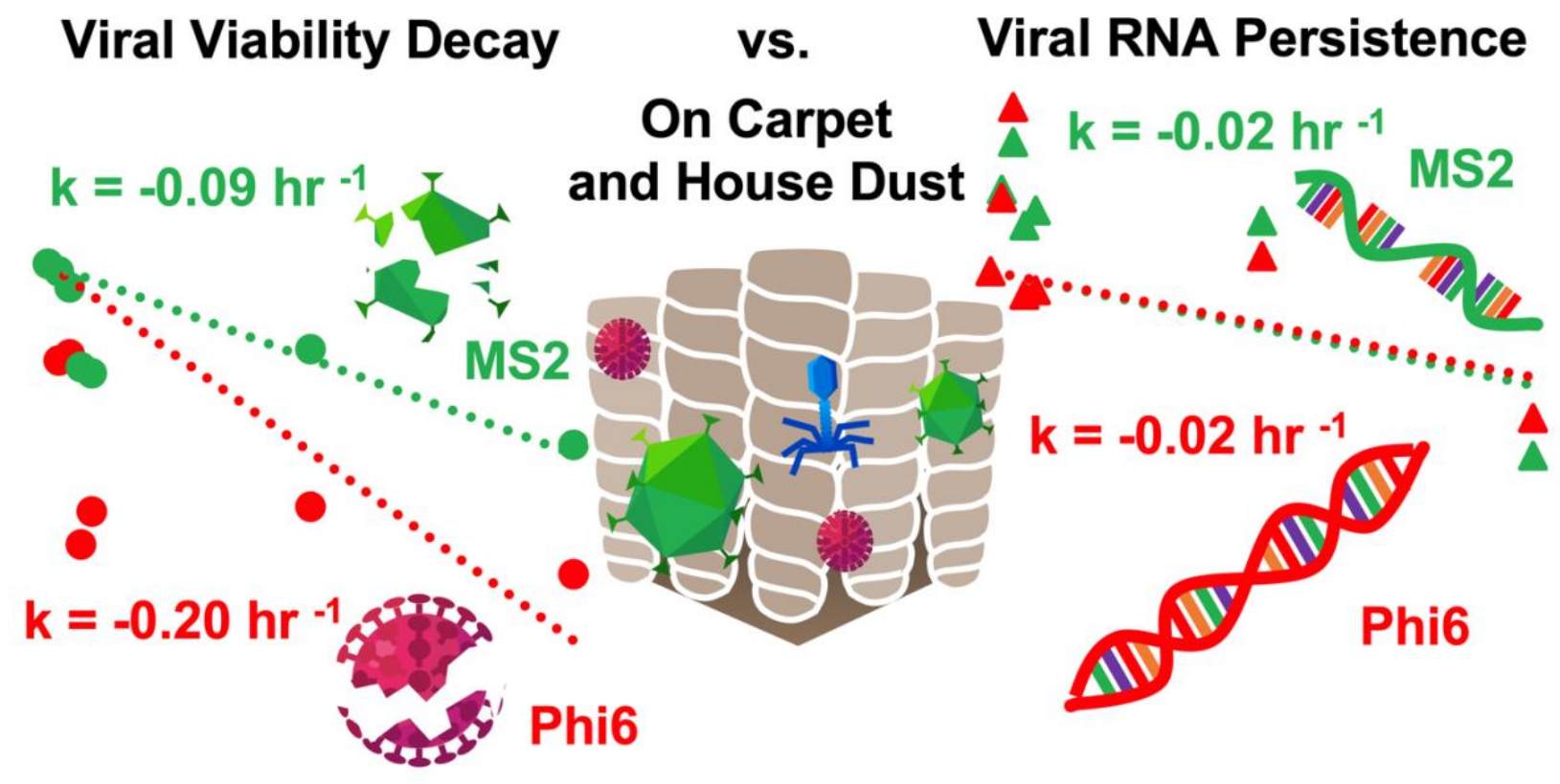




\section{Introduction}

The novel severe acute respiratory syndrome coronavirus 2 (SARS-CoV-2) has

76 resulted in more than 160 million cases and 3.3 million deaths worldwide [1] since reaching

77 pandemic designation in March 2020. Transmission occurs predominantly in the indoor

78 environment [2]. Spread occurs primarily through droplets and aerosols, though fomite

79 transmission may also contribute at a lesser level [3-5] [6][7,8]. Dust represents an intermediate

80 material that can be conceptualized as either a fomite or an aerosol. In fact, other respiratory

81 viruses can be transmitted via particulate matter and have been conceptualized as 'aerosolized

82 fomites' $[9,10]$.

Viruses, including SARS-CoV-2, can persist on contaminated surfaces or materials [5].

84 In fact, SARS-CoV-2 remains viable on plastics and stainless steel, with a half-life on the order

85 of hours [4]. A norovirus outbreak in school children followed a contamination event from an

86 infected individual who vomited in the building on the previous day [11]. Typically, enveloped

87 viruses (e.g., SARS-CoV-2, influenza) decay more rapidly on surfaces than non-enveloped

88 viruses (e.g., norovirus, adenovirus) [12]. Environmental conditions such as relative humidity

89 and the composition of carrier droplets also impact virus survival. Viruses typically remain

90 viable the longest at low relative humidity levels, and viability may decrease as relative humidity

91 increases or demonstrate a U-shaped pattern depending on droplet composition and presence of a

92 viral envelope [13]. SARS-CoV-2 is also temperature sensitive [14].

93 RNA from SARS-CoV-2 and other viruses may be present at high levels in dust [15], and

94 viruses on the floor are rapidly transported to hands and other surfaces [16]. SARS-CoV-2 has

95 been detected on outdoor particulate matter [17]. Some evidence indicates that high particulate

96 matter levels are associated with increased measles spread [18,19], although higher exposure to 
97 particulate matter could influence susceptibility separately. In fact, transmission of influenza via

98 dust has been demonstrated in guinea pigs [9], and dust may contribute to spread of avian

99 influenza [10]. However, viral persistence on indoor dust is not well understood.

100 The goal of this study is to determine persistence of two representative RNA viruses,

101 Phi6 and MS2, on indoor dust and on carpet. Both viruses are bacteriophages and have widely

102 been applied as surrogates for assessment of environmental fate of pathogenic viruses [20,21].

103 Phi6 (Ф6) has an enveloped capsid and MS2 is non-enveloped. In this study we assess viral

104 viability over time and following four common cleaning measures: disinfection, vacuuming,

105 steam cleaning, and hot water extraction with stain remover. Persistence was assessed both by

106 culture (i.e., viability) and RT-qPCR (i.e., RNA detection) methods. Results of this work have

107 important implications for understanding viral transmission in the indoor environment. This may

108 also inform recommendations for cleaning practices following viral contamination.

109 Methods

Overview

111 The persistence of viable virus in house dust and residential carpet was observed in this

112 study by using viral surrogates, MS2 and Phi6 bacteriophages. MS2 infects Escherichia coli,

113 does not have an envelope, and has single-stranded, positive-sense RNA. Phi6 infects

114 Pseudomonas syringae, has an enveloped capsid, and has double-stranded RNA.

115 To simulate viral deposition, the viral surrogates were placed in an artificial saliva

116 mixture and nebulized onto carpet and dust samples. The virus was extracted from each sample

117 using a wash and filtration step. We also evaluated carpet cleaning methods including

118 vacuuming, steam cleaning, hot water extraction with stain remover, and disinfection to examine

119 the effectiveness for inactivation or removal of the viral surrogates. For all samples, an RNA 
120 extraction and RT-qPCR analysis was performed to determine RNA quantity for each virus.

121 Plaque assays were performed to determine viability.

\section{Carpet and Dust Samples}

Carpet samples were supplied by a major manufacturer with no antimicrobial, stain

125 resistance, or soil resistance coatings. The carpets were composed of polyethylene terephthalate

126 (PET) carpet fibers and a synthetic jute backing. Two types of fiber construction processes were

127 examined that included a cut pile (fiber length $10 \mathrm{~mm}$ ) and a looped pile (fiber length $7.5 \mathrm{~mm}$ ).

128 Carpet samples consisted of a $5 \mathrm{~cm}$ x $5 \mathrm{~cm}$ square that contained a $3 \mathrm{~cm} \times 1 \mathrm{~cm}$ cutout in the

129 center that was used for viral viability and viral RNA assays to avoid edge effects. Triplicate

130 carpet samples were used for each fiber construction type at each time point.

131 House dust was collected from a residential home vacuum bag in Ohio, USA. This dust

132 was homogenized using a $300 \mu \mathrm{m}$ sieve and confirmed to be negative for SARS-CoV-2 before

133 use, using the IDT SARS-CoV-2 (2019-nCoV) CDC qPCR Probe Assay (Integrated DNA

134 Technologies, Inc., Coralville, IA, USA) as described previously [15]. Dust was placed in

135 sterilized glass dishes lined with tin foil that was previously baked $\left(500^{\circ} \mathrm{C}\right.$ for 12 hours $)$. Each

136 dish contained two $50 \mathrm{mg}$ aliquots and a total of 3 dishes (6 dust piles) were used for each time

137 point. One pile in each dish was used for viability assays and the other was used for RNA

138 extraction and quantification. Carpet and dust samples were sterilized by autoclaving for 1 hour

139 at $121^{\circ} \mathrm{C}$ and then placed in a $100^{\circ} \mathrm{C}$ oven overnight $(\sim 12 \mathrm{hrs})$ to dry. Collection of dust for this

140 study was approved by the Ohio State University Institutional Review Board (Study

141 2019B0457).

$142 \quad$ Nebulization onto carpet and validation 
Artificial saliva was created using a modified recipe [22](Table S1). Porcine gastric

144 mucin was obtained from Sigma-Aldrich (Type II, M2378) [23]. We selected $10^{8}$ plaque forming

145 units $(\mathrm{PFU}) / \mathrm{mL}$ for both MS2 and Phi6 virus as a starting concentration to mimic the viral

146 concentration of SARS-CoV-2 typically found in saliva, which ranged from $10^{4}-10^{8}$ copies/mL

147 one week after symptom onset [24]. Average viral concentrations in respiratory secretions and

148 sputum range from $2.3 \times 10^{5}$ virions $/ \mathrm{mL}$ to $1.9 \times 10^{7}$ virions $/ \mathrm{mL}$, depending on the time after

149 symptom onset [25] [26], while peak viral load appeared 10 days after symptom onset [25]. This

150 range of viral concentration in sputum was found to be similar in patients with both severe and

151 mild SARS-CoV-2 symptoms [27].

A total of $4 \mathrm{~mL}$ of the saliva with both MS2 and Phi6 (10 8 PFU/mL each) was nebulized

153 onto the carpet or dust. Nebulization of viruses onto samples were performed following a

154 modified protocol that increased the nebulizing and settling time to 15 minutes [28]. A total of

155 three nebulization runs were conducted for each time point. Each nebulization deposited the viral 156 saliva solution onto triplicate cut carpet, looped carpet, and dust samples. The triplicate samples

157 for each material type were then placed into separate incubation jars.

\section{Incubation}

After nebulization, samples were placed into a 3.8 L autoclaved glass jar for incubation.

161 A salt solution (500 mL DI water, $268 \mathrm{~g} \mathrm{MgCl}_{2}$ ) was made and placed in each jar to keep the

162 equilibrium relative humidity $(\mathrm{ERH})$ in the incubation chamber between $30-40 \%$. Water activity

163 of the salt solution was confirmed with an AquaLab 4TE (Meter Group, Pullman, WA). An

164 Onset $® \mathrm{HOBO} \circledast$ logger (Bourne, MA USA) was placed in the chamber to record temperature

165 and ERH levels during the incubations. Actual ERH measurements varied depending on the 
sample with cut carpet, looped carpet, and house dust all having different peak ERH and a different amount of time that it took to reach equilibrium (Figure S1). Incubation time points that were sampled included a time 0 (immediately after nebulization) followed by 1, 2, 3, 4, 24, and 48 hours at which time the virus was extracted from each sample. All incubation jars were

170 placed in a VWR incubator at $25^{\circ} \mathrm{C}$.

\section{Carpet Cleaning}

Several cleaning methods were evaluated for their effectiveness of inactivating Phi6 and

174 MS2 bacteriophages. For these tests, cut carpet samples were nebulized with saliva/viral mixture

175 as described above and cleaned immediately after nebulization (Time 0). Carpets were cleaned

176 using vacuuming, hot water extraction with stain remover, steam, and application of a

177 disinfectant solution. Each cleaning method was employed for 1 minute and then viruses were

178 extracted from each carpet sample. A standard canister vacuum was used for vacuuming and a

179 portable hot water extraction carpet cleaner was used for hot water extraction. The carpet cleaner

180 was equipped with a 3-inch cleaning attachment tool with bristles for water extraction. A soap

181 solution of $500 \mathrm{~mL}$ of water and $75 \mathrm{~mL}$ of a commercially available carpet stain remover was

182 heated to $60^{\circ} \mathrm{C}$ then added to the cleaning tank. Using the cleaning attachment tool, 3 sprays of

183 the cleaning solution were applied to the carpet samples. The solution was allowed to sit for 10

184 seconds and was then removed using the attachment tool. For steam cleaning, water was boiled

185 to $100^{\circ} \mathrm{C}$ in a $200 \mathrm{~mL}$ glass beaker. The carpet was placed upside down on top of the beaker so

186 that the steam made contact with the carpet (Temperature on carpet backing measured $80^{\circ} \mathrm{C}$ ). For

187 disinfection, a disinfectant spray was created with active ingredients sodium troclosene (NaDCC)

188 and hypochlorous acid $(\mathrm{HOCl})$. The solution was diluted to a $1076 \mathrm{ppm}$ available chlorine using 
18910 tablets in $946 \mathrm{~mL}$ of DI water. One spray $(\sim 2 \mathrm{~mL})$ was applied to each carpet sample and

190 allowed to sit for 1 minute before viral extraction. The disinfectant could not be removed prior to

191 washing, so disinfection may have continued in subsequent steps. All cleaning methods were

192 compared to carpets that were not cleaned but were nebulized with the same solution over two

193 experimental trials.

194 Viral extraction

For carpet samples, the pre-cut $3 \mathrm{~cm} \times 1 \mathrm{~cm}$ rectangles were pushed out and placed in a

$19650 \mathrm{~mL}$ plastic tube with $8 \mathrm{~mL}$ of PBS to wash the virus from the material similar to previous

197 extraction methods on fabric [29]. For all house dust samples, cups contained two separate 50

198 mg pre-weighed aliquots for each triplicate sample of which one was used for viability, and one

199 was used for RNA analysis. The carpet/dust and PBS were mixed by hand then vortexed. A total

200 of $4 \mathrm{~mL}$ of the wash was extracted and placed in a Amicon $®$ Ultra-4 Ultracel®-50k (Merck

201 Millipore Ltd.) filter tube and centrifuged for 7 minutes at $7000 \mathrm{rpm}$. The filtrate collected on the

202 top of the filter was collected into a $1.5 \mathrm{~mL}$ tube and the volumes recorded for each sample. The

203 process was repeated a second time using another $4 \mathrm{~mL}$ of PBS wash in order to collect enough

204 for viability and RNA analyses.

205 For viability analysis, a dilution series of 9 was made for each sample using $100 \mu \mathrm{L}$ of

206 the collected sample and $900 \mu \mathrm{L}$ of PBS. More details are below.

207 Phi6 and MS2 were extracted from samples of nebulized carpet utilizing the QIAamp

208 DSP Viral RNA Mini Kit (Qiagen, Germantown, MD) and from samples of dust utilizing the

209 RNeasy PowerMicrobiome Kit (Qiagen, Germantown, MD) respectively. $140 \mathrm{uL}$ of the

210 homogenous mixture of virus and PBS was placed in the lysis tube from the QIAamp DSP Viral

211 RNA and the extraction protocol given in the kit was followed. To extract from the dust samples, 
$21250 \mathrm{mg}$ of nebulized dust was utilized following a modified RNeasy PowerMicrobiome Kit

213 protocol using 10x the procedure recommended 2-mercaptoethanol and phenol chloroform based

214 lysis [15].

$215 \quad$ Viral propagation and enumeration

$216 \quad$ Phi6 bacteriophage

217 Pseudomonas syringae (Phi6 bacteriophage host) was grown from a frozen stock

218 (supplied by Dr. Karen Kormuth at Bethany College) on 1.5\% Luria-Bertani (LB) agar plates (20

$219 \mathrm{~g} / \mathrm{L}$ Difco ${ }^{\mathrm{TM}}$ Miller LB Broth, $10 \mathrm{~g} / \mathrm{L}$ Bacto ${ }^{\mathrm{TM}}$ Agar) for 48 hours at $25^{\circ} \mathrm{C}$. P. syringae was then

220 transferred to an LB Broth (1 L DI water, $20 \mathrm{~g}$ Difco $^{\mathrm{TM}}$ Miller LB Broth) one colony was used

221 per $8 \mathrm{~mL}$ of LB Broth. This liquid culture was incubated for 16 hours at $25^{\circ} \mathrm{C}$ while shaking at

$222180 \mathrm{rpm}$. Phi6 bacteriophage (supplied by Dr. Karen Kormuth at Bethany College) was

223 propagated using an enhanced $\mathrm{MgCl}_{2}$ solution (50 mL DI water, $50 \mathrm{~mL} \mathrm{LB}, 1.25 \mathrm{~mL}$ of $1 \mathrm{M}$

$224 \mathrm{MgCl}_{2}, 5 \mathrm{~mL}$ of $P$. syringae overnight culture, $20 \mu \mathrm{L}$ of stock Phi6) incubated for 24 hours at

$22525^{\circ} \mathrm{C}$. The enhanced solution was centrifuged for 30 minutes at $4000 \mathrm{rpm}$ and filtered through a

$2260.22 \mu \mathrm{m}$ filter. The high-titer Phi6 solution was made into a $40 \%$ glycerol solution and stored -

$22780^{\circ} \mathrm{C}$ until use. For enumeration of Phi6 bacteriophage, a $0.75 \%$ LBA $\left(20 \mathrm{~g} / \mathrm{L}\right.$ Difco ${ }^{\mathrm{TM}}$ Miller

228 LB Broth, $7.5 \mathrm{~g} / \mathrm{L}$ Bacto ${ }^{\mathrm{TM}}$ Agar) was made and when cooled to $48^{\circ} \mathrm{C}$ was infused with $P$.

229 syringae overnight culture (1 mL $P$. syringae per $10 \mathrm{~mL}$ of soft $\mathrm{LBA})$. A total of $10 \mathrm{~mL}$ of the

230 infused soft agar was pipetted into each culture plate. After the agar cooled, spot plating (Beck et

231 al 2009) of each sample dilution was performed by using six $10 \mu \mathrm{L}$ drops and was incubated for

23224 hours at $25^{\circ} \mathrm{C}$. Plaques were counted with a Darkfield Quebec ${ }^{\circledR}$ Colony Counter (Reichart,

233 Inc. Depew, NY, USA) and PFU/mL was calculated. This value was converted to PFU per

234 square centimeter of carpet and milligram of dust. 
MS2 Bacteriophage

Escherichia coli $\mathrm{F}_{\mathrm{amp}}$ (MS2 bacteriophage host) cultures were incubated in LB liquid

237 media from a frozen stock (supplied by Dr. Karl Linden and Dr. Ben Ma at University of

238 Colorado Boulder) on a shaker table at $180 \mathrm{rpm}$ and $36^{\circ} \mathrm{C}$ for 16 hours. After incubation, 1.467

$239 \mathrm{~mL}$ of this overnight culture was transferred to $200 \mathrm{~mL}$ of $\mathrm{LB}$ and incubated at $225 \mathrm{rpm}$ for an

240 additional 2.5 hours. For propagation of MS2 bacteriophage, $10 \mathrm{~mL}$ of this culture was

241 transferred to a new flask where $1.267 \mathrm{~mL}$ of $1 \mathrm{M} \mathrm{MgCl}_{2}$ and $633 \mu \mathrm{L}$ of frozen MS2 stock

242 (supplied by Dr. Karl Linden and Dr. Ben Ma at University of Colorado Boulder) were added.

243 The solution was gently mixed and allowed to sit for 25 minutes before resuming incubation at

$24436^{\circ} \mathrm{C}$ at $185 \mathrm{rpm}$ for another 2.5 hours. After propagation, cultures were centrifuged at $7000 \mathrm{rpm}$

245 and $10^{\circ} \mathrm{C}$ for 15 minutes. The supernatant was aliquoted into $1 \mathrm{~mL}$ stocks and stored at $-80^{\circ} \mathrm{C}$

246 until use. For MS2 enumeration, a 0.75\% LBA was made and when cooled E. coli $\mathrm{F}_{\mathrm{amp}}$ from the

247 2.5-hour incubation was added $\left(200 \mu \mathrm{L} \mathrm{E}\right.$. coli $\mathrm{F}_{\text {amp }}$ per $10 \mathrm{~mL}$ of $0.75 \%$ LBA $)$. The samples

248 were spotted on to the plates using the same method as the Phi6 bacteriophage and were

249 incubated at $36^{\circ} \mathrm{C}$ for 24 hours at which time $\mathrm{PFU} / \mathrm{mL}$ was counted and calculated in the same

250 manner as Phi6 bacteriophage.

\section{RT-qPCR}

In preparation for cDNA synthesis, heat shock treatments were performed to denature the

253 dsRNA segments in the Phi6 genome. For heat treatment, $5 \mathrm{uL}$ of sample was held at $100^{\circ} \mathrm{C}$ for

$2545 \mathrm{~min}$ followed by $5 \mathrm{~min}$ on ice as recommended by Gendron (2010). A heat shock treatment

255 was not used for MS2 genomes. cDNA was reverse transcribed from RNA samples using the

256 iScript cDNA Synthesis Kit (Biorad, Hercules, CA) according to the recommended reaction

257 protocol on the ProFlex PCR System (Applied Biosystems, Forest City, CA). The cDNA was 
stored at $-80^{\circ} \mathrm{C}$. MS2 and Phi6 specific primers and probes were used to determine RNA concentrations. The MS2 forward primer (5'-GTCCATACCTTAGATGCGTTAGC-3'), reverse primer (5'-CCGTTAGCGAAGTTGCTTGG-3'), and probe (5'-/56-

FAM/ACGTCGCCAGTTCCGCCATTGTCG/3BH) and the Phi6 forward primer (5’and probe (5'-/5FAM/CGGTCGTCGCAGGTCTGACACTCGC/3BH) were used in the PCR reactions [30]. The PCR final reaction mixture contained 1X TaqMan® master mix (Applied Biosystems $^{\mathrm{TM}}$ ), $1 \mu \mathrm{M}$ of forward and reverse primers, $150 \mathrm{nM}$ of MS2 probe or 300nM of Phi6 followed by 40 cycles of $94^{\circ} \mathrm{C}$ for $15 \mathrm{sec}$ and $60^{\circ} \mathrm{C}$ for $1 \mathrm{~min}$.

\section{Statistical analysis}

We evaluated decay of viral viability and RNA persistence over time on carpet and dust

274 as well as the reduction in viral viability after use cleaning techniques. The decay curves from

275 all experiments were fit to a first-order decay model. The first order decay rate constant, $\mathrm{k}\left(\mathrm{h}^{-1}\right)$,

276 can be calculated as the slope of the line $\ln \left(\mathrm{C}_{t} / \mathrm{C}_{0}\right)$ versus time where $\mathrm{C}_{\mathrm{t}}$ is the concentration of

277 the virus at any time $\mathrm{t}$ and $\mathrm{C}_{0}$ is the initial concentration of the virus at time zero. The mean of

278 triplicate measurements was calculated at each time point and used in the simple linear

279 regression analysis to calculate the first order decay rate constant. All decay rate constants,

280 regression coefficients and confidence intervals were calculated using GraphPad PRISM ver. 9 
281 (GraphPad, San Diego, CA) fixing the y-intercept to zero. Confidence bands represent the

282 boundary for all possible lines and were determined and plotted using GraphPad PRISM ver. 9.

283 Statistical correlation between the decay of MS2 and Phi6 bacteriophages in the two different

284 types of carpet (cut and loop) and dust was determined using Analysis of Covariance

285 (ANCOVA). This analysis was also performed to determine correlation between the decay of the

286 two different types of bacteriophages (MS2 and Phi6) in dust and artificial saliva. Phi6

287 bacteriophage viability decay in saliva alone was not statistically different from zero whereas

288 MS2 decay in saliva had a small growth rate that was statistically different from zero but much

289 less than the rates for decay on carpet/dust ( $\mathrm{p}=0.001$ for MS2, $\mathrm{p}=0.098$ for Phi6) (Figure S2,

290 Table S2). Comparison between untreated cut fiber carpet and carpet cleaned by vacuum, steam,

291 hot water extraction, and disinfection was done for Phi6 and MS2 bacteriophage using Kruskal-

292 Wallis test followed by Dunn's multiple comparisons test. Values below detection limit were

293 assumed to be half detection limit for Kruskal-Wallis test.

\section{Results}

296 Viral decay over time

297 In house dust, Phi6 had a faster viability decay rate $\left(-3.36 \mathrm{hr}^{-1}\right)$ compared to MS2

298 bacteriophage $\left(-0.11 \mathrm{hr}^{-1}\right)($ Figure 1, Table 1), and the difference was statistically significant

299 (ANCOVA, p=0.0001). Phi6 had faster viability decay than MS2 in both looped and cut carpet

300 type, and the difference was statistically significant for cut carpet (ANCOVA $p=0.0018$ for cut

301 and $\mathrm{p}=0.20$ for looped).

302 In the artificial saliva, MS2 had a slight positive slope and the viability decay rate for

303 Phi6 was not statistically different from zero (Figure S2, Table S2). The viability decay rates

304 were statistically different from each other (ANCOVA, $\mathrm{p}=0.0002$ ). 
For both Phi6 and MS2 bacteriophages, viability decay occurred faster in cut carpet fibers

$306\left(-1.57\right.$ and $\left.-0.20 \mathrm{hr}^{-1}\right)$ compared to looped carpet fibers $\left(-0.20\right.$ and $\left.-0.09 \mathrm{hr}^{-1}\right)$, and the difference

307 was statistically significant for Phi6 (ANCOVA p=0.0011 for Phi6, $\mathrm{p}=0.35$ for MS2). Additional

308 data including viability values and viable concentrations plots can be found in the supporting

309 information (Figures S3-S5, Tables S3-S5).

310 Decay of RNA was much slower compared to decay of viability in both carpet types and

311 in dust for both Phi6 and MS2 (Figure 2, Table 2). Decay of Phi6 RNA was not significantly

312 different from decay of MS2 RNA in looped and cut carpet but was significantly different in dust

313 (ANCOVA $\mathrm{p}=0.67$ for loop, $\mathrm{p}=0.91$ for cut and $\mathrm{p}=0.042$ for dust). MS2 RNA decay was also not

314 statistically different from zero in dust, looped and cut carpet (ANCOVA p=0.11 for loop,

$315 \mathrm{p}=0.12$ for cut and $\mathrm{p}=0.31$ for dust). Phi6 RNA decay in dust and cut carpet was statistically

316 different from zero whereas decay in looped carpet was not statistically different from zero

317 (ANCOVA $\mathrm{p}=0.01$ for dust, $\mathrm{p}=0.03$ for cut and $\mathrm{p}=0.06$ for looped). There was also no statistical

318 difference in Phi6 RNA decay between dust, looped and cut carpet types (ANCOVA p=0.07 for

319 looped/cut, $\mathrm{p}=0.19 \mathrm{dust} / \mathrm{cut}$ and $\mathrm{p}=0.57 \mathrm{dust} / \mathrm{loop})$. Additional data including raw qPCR values

320 and RNA concentrations plots can be found in the supporting information (Figures S6-S8, Tables

321 S6-S8).

a) Viability decay in looped carpet

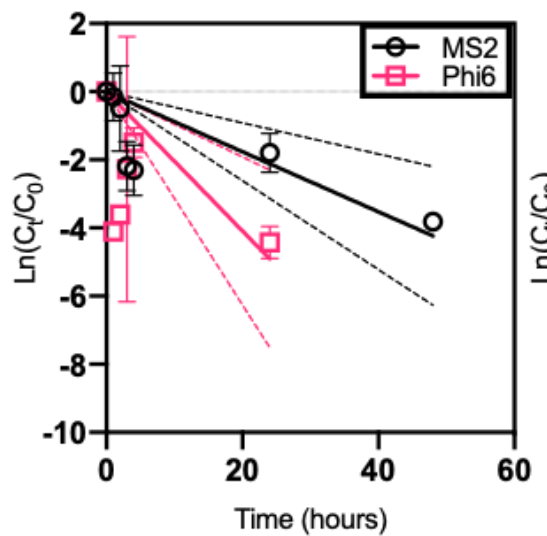

b) Viability decay in cut carpet

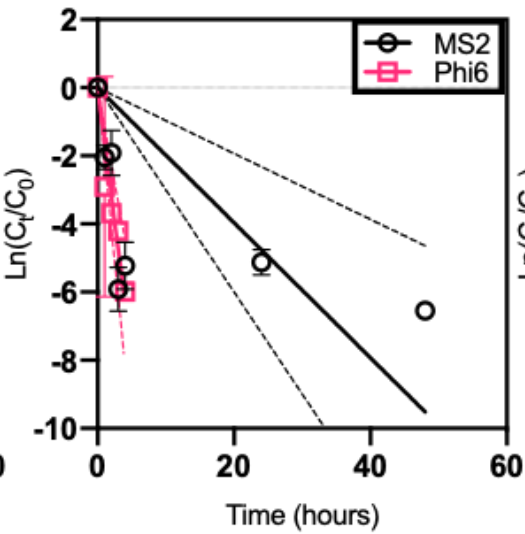

c) Viability decay in dust

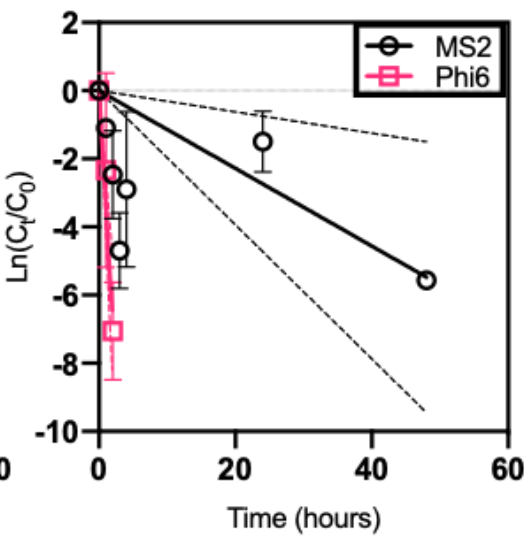

322 
323 Figure 1: Decay of MS2 and Phi6 bacteriophage viable virus in loop (a) and cut (b) carpet types and dust (c). Each

324 data point represents the average of experimental triplicate measurements from each sample type (cut carpet, looped

325 carpet, and dust) at each time point. Each point represents mean sample concentration and error bars represent the

326 standard deviation for each sample. Viable Phi6 was detectable for 24 hours for looped carpet, 4 hours for cut

327 carpet, and 2 hours in dust. Viable MS2 was detectable for the full duration of the experiment (48 hours) in all

328 conditions. Dashed lines represent 95\% confidence bands for regression lines. Detection limits for carpet, house

329 dust, and plaque assays were $6 \mathrm{PFU} / \mathrm{cm}^{2}, 0.52 \mathrm{PFU} / \mathrm{mgt}$, and $16.7 \mathrm{PFU} / \mathrm{mL}$ respectively.

a) RNA persistence in looped carpet

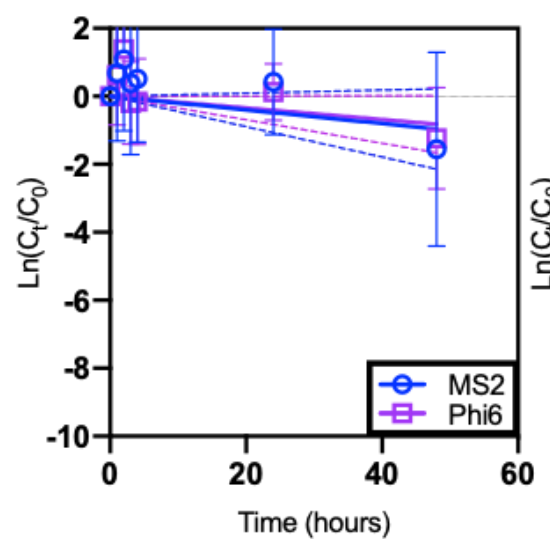

b) RNA persistence in cut carpet

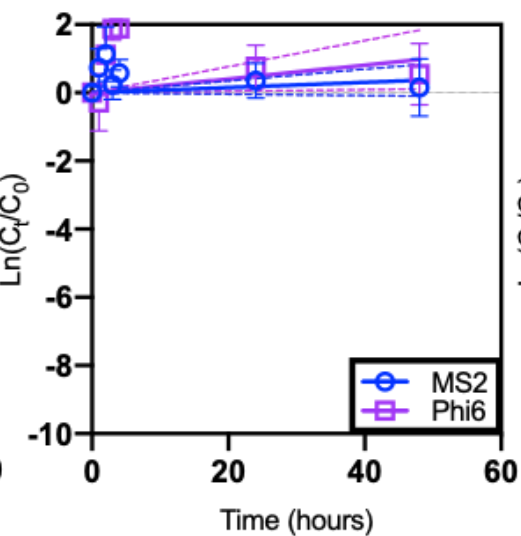

c) RNA persistence in dust

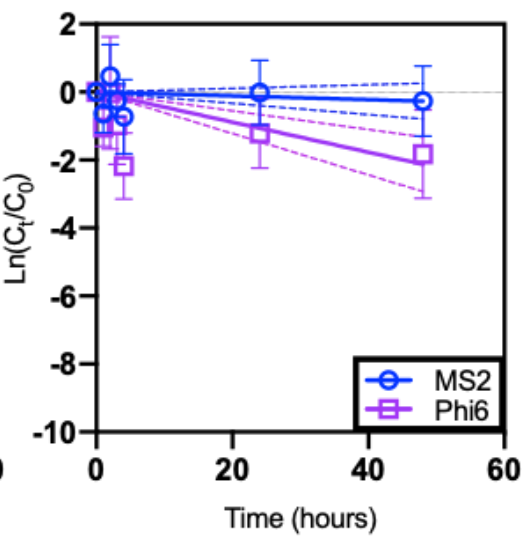

331 Figure 2: Decay of MS2 and Phi6 bacteriophage RNA in loop (a) and cut (b) carpet types and dust (c). Each data

332 point represents the average of triplicate measurements. Each point represents mean sample concentration and error

333 bars represent the standard deviation for each sample. MS2 and Phi6 RNA were detectable for the full duration of

334 experiment (48 hours) in all conditions. Dashed lines represent 95\% confidence bands for regression lines. Detection

335 limits for carpet, house dust, and plaque assays were $6 \mathrm{PFU} / \mathrm{cm}^{2}, 0.52 \mathrm{PFU} / \mathrm{mgt}$, and $16.7 \mathrm{PFU} / \mathrm{mL}$ respectively.

Table 1: Viability first-order decay rate constants for Phi6 and MS2 bacteriophage in house dust, cut and loop carpet types.

\begin{tabular}{ccccccc} 
Phage Viability & Conditions & $\mathbf{k}\left(\mathbf{h r}^{-1}\right)$ & $\mathbf{C I}$ & $\mathbf{R}^{\mathbf{2}}$ & $\mathbf{T}_{\mathbf{9 0}}$ (hrs) & $\mathbf{T}_{\mathbf{9 9}}$ (hrs) \\
\hline & Loop carpet & -0.20 & -0.31 to -0.10 & 0.49 & 11.5 & 23.0 \\
Phi6 & Cut carpet & -1.57 & -2.03 to -1.11 & 0.97 & 1.47 & 2.93 \\
& Dust & -3.36 & -4.27 to -2.44 & 0.98 & 0.69 & 1.37
\end{tabular}




\begin{tabular}{ccccccc}
\hline & Loop carpet & -0.09 & -0.13 to -0.05 & 0.72 & 26.1 & 52.3 \\
MS2 & Cut carpet & -0.20 & -0.30 to -0.10 & 0.57 & 11.6 & 23.2 \\
& Dust & -0.11 & -0.20 to -0.03 & 0.54 & 20.2 & 40.4 \\
\hline
\end{tabular}

Table 2: RNA first-order decay rate constants for Phi6 and MS2 bacteriophage in house dust, cut and loop carpet types.

\begin{tabular}{|c|c|c|c|c|c|c|c|}
\hline Phage RNA & Conditions & $\mathbf{k}\left(\mathbf{h r} \mathbf{r}^{-1}\right)$ & CI & $\mathbf{R}^{2}$ & $\mathrm{~T}_{90}(\mathrm{hrs})$ & & $\mathrm{T}_{99}(\mathrm{hrs})$ \\
\hline \multirow{3}{*}{ Phi6 } & Loop carpet & -0.02 & -0.04 to 0.00 & 0.56 & 115 & & 230 \\
\hline & Cut carpet & 0.02 & 0.00 to 0.04 & 0.14 & \multicolumn{3}{|c|}{ N/A } \\
\hline & Dust & -0.04 & -0.06 to -0.03 & 0.50 & 52.1 & & 104 \\
\hline \multirow{3}{*}{ MS2 } & Loop carpet & -0.02 & -0.05 to 0.01 & 0.36 & 135 & & 271 \\
\hline & Cut carpet & 0.01 & 0.00 to 0.02 & 0.13 & \multicolumn{3}{|c|}{ N/A } \\
\hline & Dust & -0.01 & -0.02 to 0.01 & 0.10 & 414 & & 827 \\
\hline
\end{tabular}

\section{Removal after cleaning treatments}

342 We compared concentrations of viable MS2 and Phi6 bacteriophage as well as

343 concentrations of RNA from MS2 and Phi6 bacteriophage on untreated (no cleaning), vacuumed,

344 steam treated, disinfected, and hot water extracted carpet (Figure 3). Viability concentrations

345 were below the detection limit for cut carpet cleaned with steam and disinfectant for both Phi6

346 and MS2, and concentrations of Phi6 (Kruskal-Wallis, $\mathrm{p}=0.014$ for steam and 0.030 for

347 disinfectant) and MS2 (Kruskal-Wallis, $\mathrm{p}=0.015$ for steam and $\mathrm{p}=0.028$ for disinfectant)

348 bacteriophage were statistically different on these treated carpets compared to untreated carpet. 
Hot water extraction with stain remover and vacuuming left measurable viable MS2 and Phi6 bacteriophage on the carpet fibers, and concentrations of MS2 (Kruskal-Wallis, $\mathrm{p}=0.27$ for hot water extraction and $\mathrm{p}=0.095$ for vacuuming) and Phi6 (Kruskal-Wallis, $\mathrm{p}=0.28$ for hot water extraction and $\mathrm{p}=0.62$ for vacuuming) were not statistically different on these treated carpets compared to untreated carpet (Figure 3A).

359 influence the RNA concentration of MS2 when compared to the untreated samples (Kruskal-

360 Wallis $\mathrm{p}=0.28$ for vacuum and $\mathrm{p}=0.15$ for steam). However, RNA concentrations of MS2 were

361 statistically lower when utilizing hot water extraction or a disinfectant (Kruskal-Wallis $\mathrm{p}=0.016$

362 for hot water extraction and $\mathrm{p}=0.0001$ for disinfectant). Additional raw data values for cleaning

363 method viral viability and RNA are found in Tables S9-S10.

a) Viability persistence of MS2 and Phi6

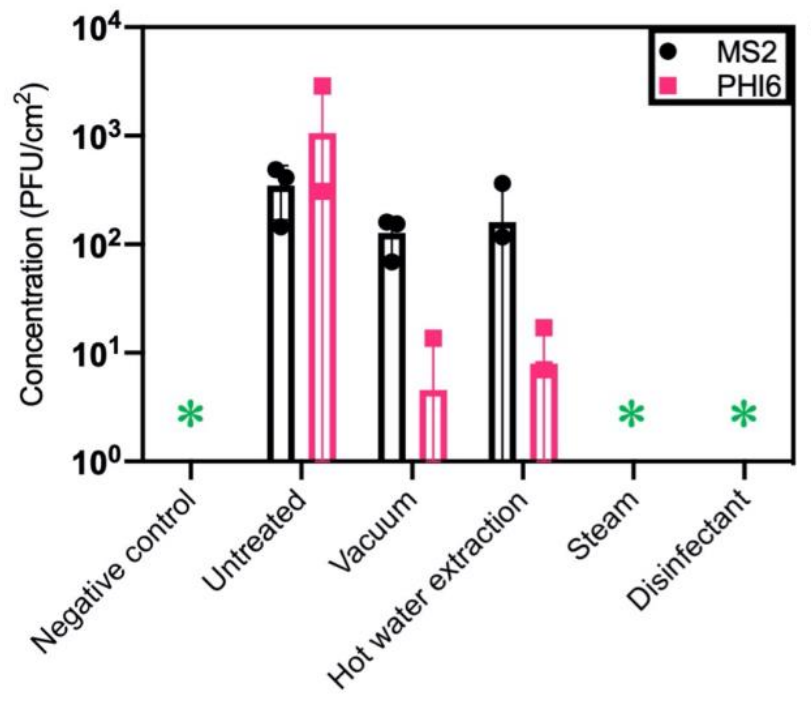

b) RNA persistence of MS2 and Phi6

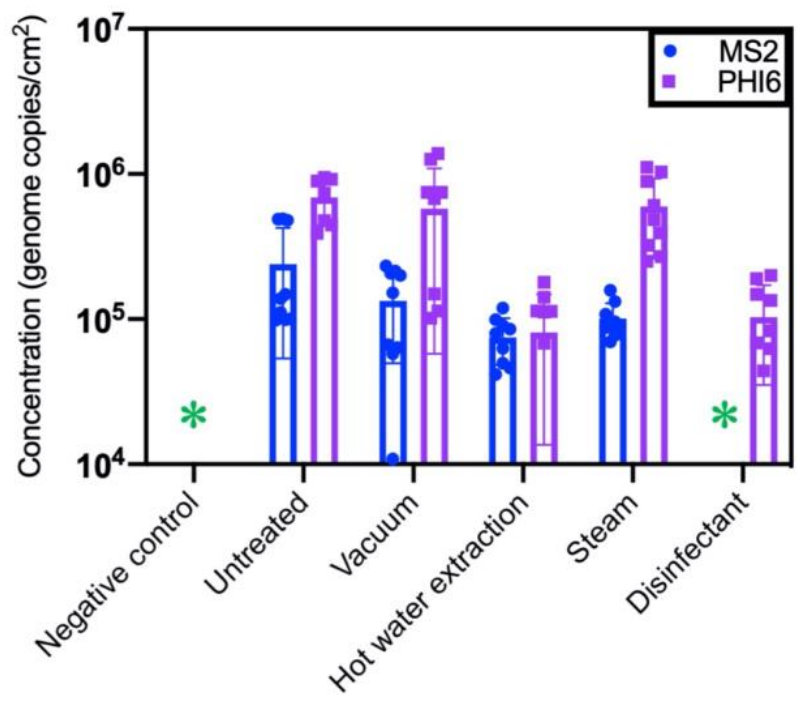


Figure 3: Concentrations of viable MS2 (black) and PHI6 bacteriophage (pink) on untreated (MS2 detected 3/3, PHI6 detected 3/3), vacuumed (MS2 detected 3/3, PHI6 detected 1/3), hot water extraction treated (MS2 detected 2/3, PHI6 detected 2/3), steam treated (MS2 detected 0/3, PHI6 detected 0/3) and disinfection treated (MS2 detected 0/3, PHI6 detected 0/3) carpets (a). Concentrations of RNA from MS2 (blue) and PHI6 (purple) bacteriophage on untreated, vacuumed, hot water extraction, steam treated, and disinfection treated carpets (b). Points represent concentration in each sample and error bars represent standard deviation. * Represents values below the detection limit. Detection limit for carpets is $6 \mathrm{PFU} / \mathrm{cm}^{2}$.

\section{Discussion}

Carpet and dust are potentially important reservoirs for microbial exposure to humans in the built environment because they serve as both a sink and a source for bacteria, fungi, and viruses [31]. Our work demonstrates that viruses can remain infective in dust for hours to days, and that the presence of a viral envelope may be an important factor in determining persistence time. Additionally, cleaning methods have a range of removal efficiencies, with methods that employ heat or disinfectants being more effective than vacuuming. RNA persisted on carpet and dust longer than viable viruses.

\section{Role of flooring in viral resuspension}

Transmission of respiratory viruses occurs predominantly in the indoor environment, and it is critical to understand viral viability on flooring and dust because these are an important source of human exposure. Exposure to virus in flooring will be influenced predominantly by two factors: 1) presence of the virus, influenced by deposition and viability decay, and 2) resuspension into the breathing zone. Regarding the former, nucleotides from SARS-CoV-2 and other viruses, like influenza, are detectable in dust and air samples, but often viability is not measured [15,32-35]. In our study, PET carpet fibers with a synthetic jute backing material were utilized and the fiber construction varied between looped pile and cut pile. Both viruses were viable longer on the loop carpet compared to the cut carpet. 
Resuspension of dust due to walking is an important contributor to human exposure,

394 particularly in carpeted areas [36]. The resuspension of dust in flooring however is also likely

395 impacted by type of flooring material such as looped carpet, cut pile carpet and hard flooring

$396[37,38]$. A recent study posited that a possible source of aerosolized SARS-CoV-2 is due to the

397 resuspension of floor dust from walking in areas with confirmed positive patients [39]. Dust

398 particles contaminated with influenza virus may be resuspended and serve as aerosolized fomites

399 of viable influenza virus [9,40]. In fact, the concentration of the resuspended influenza virus was

$40040 \%$ higher at one meter than two meters, such that shorter people and children may be more

401 likely to come in contact with these particles [40]. Understanding the resuspension of SARS-

402 CoV-2 and other viruses in carpet will be important in measuring exposure route, and

403 resuspension models are needed to determine the rate of resuspension of SARS-COV-2 in

404 varying carpet types.

405

406 Viral envelope may impact persistence on flooring and dust

407 The presence of carpets has been linked to viral infections, especially for nonenveloped

408 viruses. In one instance, carpet fibers still contained Norwalk-like viruses 13 days after the last

409 infection [41]. Outbreaks of the nonenveloped human norovirus have also been linked to viral

410 transfer of surfaces such as cotton and polyester [42]. In one study, human norovirus surrogates

411 were determined to survive for $\sim 15$ days on carpet fibers depending on relative humidity

412 condition and fiber type [43]. Non-enveloped viruses, such as rotavirus and poliovirus, persist for

413 up to two months on surfaces [44,45], while enveloped respiratory viruses, such as H1N1, human

414 coronaviruses and SARS-CoV, persist for several hours to days [46][47]. 
417 similarly to that of Phi6, and this can be evaluated in future studies. We used a first-order

418 equation to model viral viability decay. Model fit may have been influenced by variability

419 inherent in sample processing, which may be due to differences in nebulization, carpet wash

420 steps, and viral plaque assays in general. However, the trend was clear that Phi6 viability decays

421 more quickly than MS2. RNA from both bacteriophages persisted longer than viability.

423 different viability decay rates based on carpet fiber type and on carpet compared to dust. SARS-

424 CoV-1 survives on metal, wool, paper, glass, and plastic for 4 - 5 days [48-50]. In other cases,

425 on non-porous surfaces such as glass, stainless steel and vinyl, infectious SARS-CoV-2 was

426 detected after 28 days; however, it was not detected on the porous material cotton cloth after 14

427 days at $20^{\circ} \mathrm{C}$ potentially due to an immediate absorption effect [14]. Persistence of SARS-CoV-2

428 on plastic (e.g., PET, which is the same material of our carpet) lasts for up to 72 hours and in one

429 study had the longest viability of materials tested [4].

\section{Relative humidity and virus viability}

Airborne viruses are sensitive to humidity conditions. Viruses remain viable the longest

433 at low relative humidity, and viability may decrease as relative humidity increases or

434 demonstrate a U-shaped pattern (high-low-high) depending on droplet composition and presence

435 of a viral envelope [13]. SARS-CoV-2 is most stable at low relative humidity $(<40 \%)$ and

436 stability decreases as relative humidity is increased between 50 - 90\% [51]. Virus viability

437 rapidly decays at high temperatures $\left(38^{\circ} \mathrm{C}\right)$ and high relative humidity (>95\%) [49]. Other 
438 studies have determined that saturated humidity conditions may facilitate the spread of the

439 SARS-CoV-2 via cluster spread [52]. At elevated humidity conditions between $65 \%-100 \%$

440 aerosolized SARS-CoV-2 may be viable for up to 3 hours [4]. In this study the relative humidity

441 was maintained $\sim 30 \%$ to mimic realistic home environment conditions, however due to

442 incubation limitations this humidity level varied between 40-90\% early in the incubation

443 depending on the sample (Figure S1). The variation between carpet fiber structures could change

444 the moisture retention properties and thus impact the decay rates for MS2 and Phi6

445 bacteriophages. However, this variation in carpet fiber construction is realistic in real-world

446 building environments and should be investigated further to examine its effect on viral-saliva

447 droplet deposition and evaporation. Elevated humidity conditions in carpet dust are known to

448 influence fungal growth $[53,54]$ and this humidity may influence the viability and stability of

449 viruses in carpet dust. Continued work is needed to fully understand how elevated humidity in

450 carpet may impact the viability as well as the stability of SARS-CoV-2 and other viruses in dust.

\section{Differential viral removal efficacy of cleaning methods}

Inactivation or removal of viruses from house dust or residential carpets is an important

453 tool that can be used to reduce viral transmission in indoor environments. Vacuuming is a

454 common housekeeping routine used to remove accumulated soils from carpet. This method

455 reduced viable viruses on our carpet samples, when compared to carpet samples that were not

456 cleaned, but the viable virus was still detectable in the carpet afterward. However, vacuuming,

457 and hot water extraction removed viable Phi6 (enveloped) more effectively compared to MS2

458 (non-enveloped). Vacuuming could also resuspend viral particles into the air [55]. Similarly, hot

459 water extraction is often used to maximize physical removal of soils in carpet and is readily

460 available for use in homes. This cleaning method reduced viable virus on carpet samples, but 
461 viruses were still detected after cleaning and the difference was not statistically significant.

462 Applying steam to carpet samples reduced virus viability to below detectable limits but is not

463 necessarily realistic for in-home decontamination of carpets. The application of a disinfectant to

464 the carpet samples also reduced viruses to below detectable limits, although disinfectant may

465 have continued to contact the virus during the wash step of our experiment. Disinfectants are an

466 easy and realistic method building occupants may use to inactivate viruses on carpet following

467 viral illness. These factors are likely to be most important in commercial/public, high-risk areas

468 such as hospitals, and may only be relevant in residential settings under unique circumstances.

$470 \quad$ Limitations

$471 \quad$ All carpet and dust samples were autoclaved before nebulization of viruses. However,

472 due to the complexity of these samples it is likely that bacterial and fungal quantities were

473 substantially reduced but not completely sterilized [56] A salt solution was used to attempt to

474 maintain ERH in the incubation chambers at 30-40\%. However, each sample type (dust, cut, and

475 looped carpet) showed different absorption of nebulized saliva, which affected the peak ERH and

476 the time in which it took to lower to under 50\% ERH. Cut carpet peaked close to 90\%, looped

477 carpet approximately $80 \%$, and dust at $60 \% \mathrm{ERH}$ while taking 12, 6, and 3 hours respectively to

478 reach 50\% ERH. These differences in ERH and duration may have affected the decay rates of

479 each viral surrogate in this study, although carpet structure might also reflect moisture retention

480 in carpets in buildings. This may have also resulted in suboptimal first-order model fit, in

481 addition to other factors that contributed to variation including variability in nebulization, carpet

482 wash steps, and viral plaque assay limitations. Other models, such as biphasic decay, require

483 more data points for accurate curve fit and could be evaluated in future studies. During 
484 aerosolization and deposition of the viral surrogates onto these samples, phage aggregates may

485 have formed. This could create an uneven distribution among samples leading to an

486 underestimation of the viable virus observed on carpet and in dust [30]. Different lab personnel

487 performed the cleaning methods and time series viability testing, therefore user differences in the

488 nebulization, carpet/dust extraction, and plaque assay protocols may have been introduced. For

489 the disinfection cleaning method, we were unable to determine if viral viability was lost from

490 contact on the carpet or while it was mixed during the viral wash extraction protocol.

491 This study used bacteriophage viral surrogates, which are different from human

492 pathogenic viruses. Bacteriophages are considered good surrogates to study airborne viruses.

493 These viruses can be produced in large quantities, pose little hazard for laboratory workers, and

494 do not require specialized containment protocols [21]. The bacterial viruses MS2 and Phi6 were

495 chosen for this work because of their similarities with known pathogenic viruses, including

496 SARS-CoV-2 [20,21,57,58]. However, these are different viruses, and real pathogens may

497 behave differently.

499 Implications

These results suggest that viable viruses can persist on dust and carpet for hours to days

501 depending on viral structure and environmental conditions, but more information is needed to

502 understand risk. RNA persists longer than viable viruses and may be useful for surveillance

503 methods [15]. This current study was based on bacteriophages, and additional research is needed

504 using human viruses in the appropriate biosafety facilities to confirm the results, followed by risk

505 modeling. Additionally, many enveloped viruses (including SARS-CoV-2 and others) may only

506 remain infectious in dust for a very brief period of time (on the order of hours post-deposition). 
507 Thus, transmission may only be possible shortly after deposition, when expelled respiratory

508 aerosols may also continue to be a transmission risk in the same space. Cleaning of such spaces

509 could be delayed by several hours to reduce infection risk to maintenance staff. Non-enveloped

510 viruses (norovirus and others) may be more easily transmitted via flooring over longer periods of

511 time, and appropriate cleaning techniques using heat and/or disinfectants may be more critical to

512 reduce infection risk. Unfortunately, in many cases the virus causing infection may not have

513 been identified prior to the need for an environment to be cleaned, so it may be prudent to both

514 wait some time if the room can be vacated and then employ heat-based or disinfection-based

515 methods, when possible, to clean contaminated flooring.

$516 \quad$ Ultimately, future research can improve our understanding of dust as a potential

517 transmission route for viral infection. Risk modeling should follow this analysis. This may have

518 important implications for reducing viral spread in the general population, and also for custodial

519 and cleaning staff who may be working closely to clean contaminated flooring. A more nuanced

520 recognition of this potential exposure pathway can help contribute to the fight against viral

521 illnesses such as influenza and COVID-19.

\section{Acknowledgements}

524 We appreciate Dr. Karl Linden and Dr. Ben Ma at the University of Colorado Boulder for

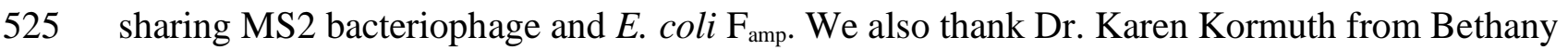

526 College for sharing Phi6 bacteriophage and Pseudomonas syringae, as well as her culturing

527 expertise related to these isolates. We thank the carpet manufacturer for the donation of carpet

528 samples. This work was funded through faculty startup funds at The Ohio State University. We

529 also want to acknowledge grant 1942501 from NSF, grant G-2018-1124 from the Alfred P. Sloan 
530 Foundation, and grant 80NSSC19K0429 from NASA, which allowed us to develop the expertise

531 to conduct this analysis. This manuscript represents the views of the authors and has not been

532 reviewed by funding agencies.

\section{Conflicts of Interest}

All authors declare no conflicts of interest.

\section{References}

1. Coronavirus disease (COVID-19) - World Health Organization. [cited 13 May 20201.

Available: https://www.who.int/emergencies/diseases/novel-coronavirus-2019

2. Qian H., Miao T., Liu L., Zheng X., Luo D., Li Y. Indoor transmission of SARS-CoV-2.

3. Jing Q. L., Liu M. J., Zhang Z. B., Fang L. Q., Yuan J., Zhang A. R., Dean, N. E., Luo, L., Ma M. M., Longini, I., Kenah, E., Lu, Y., Ma, Y., Jalali, N., Yang, Z. C., Yang, Y. Household secondary attack rate of COVID-19 and associated determinants in Guangzhou, China: a retrospective cohort study. Lancet Infect Dis. 2020, 10, 1141-1150.

4. van Doremalen N., Bushmaker T., Morris D. H., Holbrook M. G., Gamble A., Williamson

5. Aboubakr H. A., Sharafeldin T. A., Goyal S. M. Stability of SARS-CoV-2 and other coronaviruses in the environment and on common touch surfaces and the influence of climatic conditions: A review. Transbound Emerg Dis. 2020, 68, 296-312. doi:10.1111/tbed.13707

6. Vuorinen V., Aarnio M., Alava M., Alopaeus V., Atanasova N., Auvinen M., Balasubramanian, N., Bordbar, H., Erasto, P., Grande, R., Hayward, N., Hellsten, A., Kuusela, A. J., Lestinen, S., Laurila, E., Nieminen, H. J., Peltonen, P., Pokki, J., Puisto, A., Raback, P., Salmenjoki, H., Sironen, T., Osterber, M. Modelling aerosol transport and virus exposure with numerical simulations in relation to SARS-CoV-2 transmission by inhalation indoors. Saf Sci. 2020, 130, 104866.

561 7. Miller S. L., Nazaroff W. W., Jimenez J. L., Boerstra A., Buonanno G., Dancer S. J., 
Kurnitski, J., Marr, L. C., Morawska, L., Noakes, C. Transmission of SARS-CoV-2 by inhalation of respiratory aerosol in the Skagit Valley Chorale superspreading event. Indoor Air. 2020, 31, 314-323. doi:10.1111/ina.12751

8. Allen J. G., Marr L. C. Recognizing and controlling airborne transmission of SARS-CoV-2

9. Asadi S., Gaaloul Ben Hnia N., Barre R. S., Wexler A. S., Ristenpart W. D., Bouvier N. M.

10. Zhao Y., Richardson B., Takle E., Chai L., Schmitt D., Xin H. Airborne transmission may have played a role in the spread of 2015 highly pathogenic avian influenza outbreaks in the United States. Sci Rep. 2019, 9, 11755. doi:10.1038/s41598-019-47788-z

11. Evans M. R., Meldrum R., Lane W., Gardner D., Ribeiro C. D., Gallimore C. I., Westmoreland, D. An outbreak of viral gastroenteritis following environmental contamination at a concert hall. Epidemiol Infect. 2002, 129, 355-360. doi:10.1017/s0950268802007446

12. Firquet S., Beaujard S., Lobert P. E., Sané F., Caloone D., Izard D., Hober, D. Survival of Enveloped and Non-Enveloped Viruses on Inanimate Surfaces. Microbes Environ. 2015, $30,140-144$.

13. Lin K., Schulte C. R., Marr L. C. Survival of MS2 and $\Phi 6$ viruses in droplets as a function of relative humidity, $\mathrm{pH}$, and salt, protein, and surfactant concentrations. PLoS One. 2020, $15, \mathrm{e} 0243505$.

14. Riddell S., Goldie S., Hill A., Eagles D., Drew T. W. The effect of temperature on persistence of SARS-CoV-2 on common surfaces. Virol J. 2020, 17, 145.

15. Renninger N., Nastasi N., Bope A., Cochran S. J., Haines S. R., Balasubrahmaniam N., Stuart, K., Bivins, A., Hull, N. M., Bibby, K., Dannemiller, K. C. Indoor Dust as a Matrix for Surveillance of COVID-19. mSystems. 2021, 6, e01350-20. doi:10.1128/mSystems.01350-20

16. Koganti S., Alhmidi H., Tomas M. E., Cadnum J. L., Jencson A., Donskey C. J. Evaluation of Hospital Floors as a Potential Source of Pathogen Dissemination Using a Nonpathogenic Virus as a Surrogate Marker. Infect Control Hosp Epidemiol. 2016, 37, 1374-1377.

17. Setti L., Passarini F., De Gennaro G., Barbieri P., Perrone M. G., Borelli M., Palmisani, J., Di Gilio, A., Torboli, V., Fontana, F., Clemente, L., Pallavicini, A., Ruscio, M., Piscitelli, P., Miani, A. SARS-Cov-2 RNA found on particulate matter of Bergamo in Northern Italy: First evidence. Environ Res. 2020, 188, 109754.

18. Alexander R., Nugent C., Nugent K. The Dust Bowl in the US: An Analysis Based on Current Environmental and Clinical Studies. Am J Med Sci. 2018, 356, 90-96.

19. Chen G., Zhang W., Li S., Williams G., Liu C., Morgan G. G., Jaakkola J. J. K., Guo, Y. et 
al. Is short-term exposure to ambient fine particles associated with measles incidence in China? A multi-city study. Environ Res. 2017, 156, 306-311. doi:10.1016/j.envres.2017.03.046

20. Aquino de Carvalho N., Stachler E. N., Cimabue N., Bibby K. Evaluation of Phi6 Persistence and Suitability as an Enveloped Virus Surrogate. Environ Sci Technol. 2017, 51,

21. Turgeon N., Toulouse M. J., Martel B., Moineau S., Duchaine C. Comparison of Five Bacteriophages as Models for Viral Aerosol Studies. Appl Environ Microbiol. 2014, 80, 4242.

22. Woo M. H., Hsu Y. M., Wu C. Y., Hemibuch B., Wander J. Method for contamination of filtering facepiece respirators by deposition of MS2 viral aerosols. J Aerosol Sci. 2010, 41, 944-952.

23. Mao Y., McClements D. J. Influence of electrostatic heteroaggregation of lipid droplets on their stability and digestibility under simulated gastrointestinal conditions. Food Funct. 2012, 3, 1025-1034. doi:10.1039/c2fo30108c

24. Zhu J., Guo J., Xu Y., Chen X. Viral dynamics of SARS-CoV-2 in saliva from infected patients. J Infect. 2020, 81, e48-e50.

25. Peiris J. S. M., Chu C. M., Cheng V. C. C., Chan K. S., Hung I. F. N., Poon L. L. M., Law K. I., Tang, B. S., Hon, T. Y., Chan, C. S., Chan, K. H., Ng, J. S., Zheng, B. J., Ng, W. L., Lai, R. W., Guan, Y., Yuen, K. Y. Clinical progression and viral load in a community outbreak of coronavirus-associated SARS pneumonia: a prospective study. Lancet. 2003, 361, 1767-1772. doi:10.1016/s0140-6736(03)13412-5

26. Pan Y., Zhang D., Yang P., Poon L. L. M., Wang Q. Viral load of SARS-CoV-2 in clinical samples. Lancet Infect Dis. 2020, 20, 411-412. doi:10.1016/s1473-3099(20)30113-4

27. Zheng S., Fan J., Yu F., Feng B., Lou B., Zou Q., Xie G., Lin, S., Wang, R., Yang, X., Chen, W., Wang, Q., Zhang, J., Yao, H., Xu, K., Lu, X., Wei, G., Zhou, J., Fang, Q., Cai, H., Qiu, Y., Sheng, J., Chen, Y., Liang, T. Viral load dynamics and disease severity in patients infected with SARS-CoV-2 in Zhejiang province, China, January-March 2020: retrospective cohort study. BMJ. 2020, 369, m1443.

28. Nastasi N., Haines S. R., Xu L., da Silva H., Divjan A., Barnes M. A., Rappleye, C. A., Perzanowski, M. S., Green, B. J., Dannemiller, K. C. Morphology and quantification of fungal growth in residential dust and carpets. Build Environ. 2020, 174, 106774. doi:10.1016/j.buildenv.2020.106774

29. Malik Y. S., Allwood P. B., Hedberg C. W., Goyal S. M. Disinfection of fabrics and carpets artificially contaminated with calicivirus: relevance in institutional and healthcare centres. $J$ Hosp Infect. 2006, 63, 205-210.

634 30. Gendron L., Verreault D., Veillette M., Moineau S., Duchaine C. Evaluation of Filters for 
the Sampling and Quantification of RNA Phage Aerosols. Aerosol Sci Technol. 2010, 44, 893-901.

31. Haines S. R., Adams R. I., Boor B. E., Bruton T. A., Downey J., Ferro A. R., Gall, E., Green, B. J., Hegarty, B., Horner, E., Jacobs, D. E., Lemieux, P., Misztal, P. K., Morrison, G., Perzanowski, M. S., Reponen, T., Rush, R. E., Virgo, T., Alkhayri, C., Bope, A., Cochran, S. J., Cox, J., Donohue, A., May. A. A., Nastasi, N., Nishioka, M., Renninger, N., Tian, Y., Uebel-Niemeier, C., Wilkinson, D., Wu, T., Zambrna, J., Dannemiller, K.C. Ten questions concerning the implications of carpet on indoor chemistry and microbiology. Build Environ. 2019, 170, 1-16.

32. Fernández-Raga M., Díaz-Marugán L., García Escolano M., Bort C., Fanjul V. SARS-CoV2 viability under different meteorological conditions, surfaces, fluids and transmission between animals. Environ Res. 2020, 192, 110293.

33. Chen P. S., Tsai F. T., Lin C. K., Yang C. Y., Chan C. C., Young C. Y., Lee, C. H. Ambient Influenza and Avian Influenza Virus during Dust Storm Days and Background Days. Environ Health Perspect. 2010, 118, 1211-1216. doi:10.1289/ehp.0901782

34. Woźniakowski G., Samorek-Salamonowicz E. Direct detection of Marek's disease virus in poultry dust by loop-mediated isothermal amplification. Arch Virol. 2014, 159, 3083-3087.

35. Han T. H., Park S. H., Chung J. Y., Jeong H. W., Jung J., Lee J. I., Hwang, Y. O., Kim, I. Y., Lee, J. H., Jung, K. Detection of Pathogenic Viruses in the Ambient Air in Seoul, Korea. Food Environ Virol. 2018, 10, 327-332.

36. Qian J., Ferro A. R. Resuspension of Dust Particles in a Chamber and Associated Environmental Factors. Aerosol Sci Tech. 2008, 42, 566-578. doi:10.1080/02786820802220274

38. Lewis R. D., Ong K. H., Emo B., Kennedy J., Kesavan J., Elliot M. Resuspension of house

37. Tian Y., Sul K., Qian J., Mondal S., Ferro A. R. A comparative study of walking-induced dust resuspension using a consistent test mechanism. Indoor Air. 2014, 24, 592-603. dust and allergens during walking and vacuum cleaning. J Occup Environ Hyg. 2018, 15, 235-245. doi:10.1080/15459624.2017.1415438

39. Liu Y., Ning Z., Chen Y., Guo M., Liu Y., Gali N. K., Sun, L., Duan, Y., Cai, J., Westerdahl, D., Liu, X., Xu, K., Ho, K. F., Kan, H., Fu, Q., Lan, K. Aerodynamic Characteristics and RNA Concentration of SARS-CoV-2 Aerosol in Wuhan Hospitals during COVID-19 Outbreak. Nature. 2020, 582, 2020.03.08.982637. doi:10.1101/2020.03.08.982637

40. Khare P., Marr L. C. Simulation of vertical concentration gradient of influenza viruses in dust resuspended by walking. Indoor Air. 2015, 25, 428-440. survival of small round structured viruses. J Hosp Infect. 1997, 35, 325-326. 
42. Lopez G. U., Gerba C. P., Tamimi A. H., Kitajima M., Maxwell S. L., Rose J. B. Transfer Efficiency of Bacteria and Viruses from Porous and Nonporous Fomites to Fingers under Different Relative Humidity Conditions. Appl Environ Microbiol. 2013, 79, 5728-5734.

43. Buckley D., Fraser A., Huang G., Jiang X. Recovery Optimization and Survival of the Human Norovirus Surrogates Feline Calicivirus and Murine Norovirus on Carpet. Appl Environ Microbiol. 2017, 83, e01336-17. doi:10.1128/AEM.01336-17

44. Kramer A., Schwebke I., Kampf G. How long do nosocomial pathogens persist on inanimate surfaces? A systematic review. BMC Infect Dis. 2006, 6, 130. doi:10.1186/14712334-6-130

45. Howie R., Alfa M. J., Coombs K. Survival of enveloped and non-enveloped viruses on surfaces compared with other micro-organisms and impact of suboptimal disinfectant exposure. J Hosp Infect. 2008, 69, 368-376.

46. Duizer E., Bijkerk P., Rockx B., De Groot A., Twisk F., Koopmans M. Inactivation of caliciviruses. Appl Environ Microbiol. 2004, 70, 4538-4543.

47. Geller C., Varbanov M., Duval R. E. Human coronaviruses: insights into environmental resistance and its influence on the development of new antiseptic strategies. Viruses. 2012, 4, 3044-3068.

48. Duan S. M., Zhao X. S., Wen R. F., Huang J. J., Pi G. H., Zhang S. X., Han, J., Bi, S. L., Ruan, L., Dong, X. P. Stability of SARS coronavirus in human specimens and environment and its sensitivity to heating and UV irradiation. Biomed Environ Sci. 2003, 16, 246-255.

49. Chan K. H., Peiris J. S. M., Lam S. Y., Poon L. L. M., Yuen K. Y., Seto W. H. The Effects of Temperature and Relative Humidity on the Viability of the SARS Coronavirus. Adv Virol. 2011, 2011, 734690.

50. Kampf G., Todt D., Pfaender S., Steinmann E. Persistence of coronaviruses on inanimate surfaces and their inactivation with biocidal agents. J Hosp Infect. 2020, 104, 246-251.

51. Biryukov J., Boydston J. A., Dunning R. A., Yeager J. J., Wood S., Reese A. L., Derris, A., Miller, D., Weaver, W., Zeitouni, N. E., Phillips, A., Freeburger, D., Hooper, I., RatnesarShumate, S., Yolitz, J., Krause, M., Williams , G., Dawson, D. G., Herzog, A., Dabisch, P., Wahl, V., Hevey, M. C., Altamura, L. A. Increasing Temperature and Relative Humidity Accelerates Inactivation of SARS-CoV-2 on Surfaces. mSphere. 2020, 5, e00441-20. doi:10.1128/mSphere.00441-20

52. Luo C., Yao L., Zhang L., Yao M., Chen X., Wang Q., Shen, H. Possible Transmission of Severe Acute Respiratory Syndrome Coronavirus 2 (SARS-CoV-2) in a Public Bath Center in Huai'an, Jiangsu Province, China. JAMA Netw Open. 2020, 3, e204583.

53. Dannemiller K. C., Weschler C. J., Peccia J. Fungal and bacterial growth in floor dust at elevated relative humidity levels. Indoor Air. 2017, 27, 354-363. 
54. Haines S. R., Siegel J. A., Dannemiller K. C. Modeling microbial growth in carpet dust exposed to diurnal variations in relative humidity using the "Time-of-Wetness" framework. Indoor Air. 2020, 30, 978-992.

55. Seo Y., Han T. Assessment of penetration through vacuum cleaners and recommendation of wet cyclone technology. J Air Waste Manag Assoc. 2013, 63, 453-461.

56. Wolf D. C., Dao T. H., Scott H. D., Lavy T. L. Influence of Sterilization Methods on Selected Soil Microbiological, Physical, and Chemical Properties. J Environ Qual. 1989, 18, 39-44. doi:10.2134/jeq1989.00472425001800010007x

57. Verreault D., Moineau S., Duchaine C. Methods for Sampling of Airborne Viruses. Microbiol Mol Biol Rev. 2008, 72, 413-444. doi:10.1128/mmbr.00002-08

58. Fedorenko A., Grinberg M., Orevi T., Kashtan N. Survival of the enveloped bacteriophage Phi6 (a surrogate for SARS-CoV-2) in evaporated saliva microdroplets deposited on glass surfaces. Sci Rep. 2020, 10, 22419. 